\title{
Interleukin-6 versus C-reactive Protein as Markers for Early Detection of Bacteremia in Febrile Neutropenia in Pediatric Population
}

\begin{abstract}
Introduction: Systemic infection leading to multiorgan failure during neutropenia is one of the leading causes of treatment-related mortality among children receiving chemotherapy. Reliable markers are needed to diagnose or rule out infection, to reduce the empirical use of broad-spectrum antibiotic therapy. Aims and Objectives: The aim is to compare the role of interleukin-6 versus C-reactive protein (CRP) as markers of sepsis in febrile neutropenia in pediatric patients while on chemotherapy for malignancy. Materials and Methods: This was a prospective observational study carried out in the Department of Paediatrics of a tertiary care Hospital in South India. All children with malignancy in the age group from 1 month to 18 years diagnosed to have febrile neutropenia during any phase of chemotherapy were included in the study. Multiple episodes of febrile neutropenia in the same child were analyzed as separate episodes. Results: Thirty-two episodes of febrile neutropenia were analyzed. There were 7 microbiologically documented infections (MDI), 19 clinically documented infections and 6 episodes of fever of unknown origin. Out of the 7 MDI, 5 were Gram-negative sepsis and 2 were Gram-positive sepsis. Gram-negative sepsis had a much higher median IL-6 value (169) than Gram-positive sepsis (17.5) and sterile blood cultures (52). However, median value of CRP was only slightly higher in Gram-positive sepsis (85.5) than in Gram-negative sepsis (60.7) and sterile blood cultures (44.2). Conclusion: In this study, higher IL-6 values predicted Gram-negative sepsis better than CRP.
\end{abstract}

Keywords: C-reactive protein, febrile neutropenia, interleukin-6

\section{Introduction}

Systemic infection leading to multi-organ failure during episodes of neutropenia is one of the major causes of treatment-related mortality in children on chemotherapy. ${ }^{[1]}$ Fever is the first symptom of infection in neutropenic patients. However, apart from infection, fever can also be due to reaction to drugs, blood products, and tumor-associated fever. ${ }^{[1]}$

Empirical antibiotic therapy is usually started immediately when fever develops in neutropenic patients as bacterial infections can be life-threatening for such patients. Therefore, reliable markers are needed to diagnose or rule out infection, which will reduce the use of empirical broad-spectrum antibiotics and facilitate targeted and specific therapy as soon as possible. The most common marker used is C-reactive protein (CRP), an acute-phase reactant whose concentration rises within $24 \mathrm{~h}$ of

This is an open access journal, and articles are distributed under the terms of the Creative Commons Attribution-NonCommercial-ShareAlike 4.0 License, which allows others to remix, tweak, and build upon the work non-commercially, as long as appropriate credit is given and the new creations are licensed under the identical terms.

For reprints contact: WKHLRPMedknow_reprints@wolterskluwer.com a microbial infection. Interleukin-6 (IL-6) is a cytokine whose levels increase after stimulation with IL-1, endotoxin or tumor necrosis factor alpha. ${ }^{[1,2]}$ Although the concentration of both IL-6 and CRP is higher in patients with infections caused by bacteria as compared to viruses, IL-6 has been reported as a more sensitive and early marker for bacteremia especially Gram-negative bacteremia. ${ }^{[3,4]}$ IL-6 levels have been studied to rise as early as $1 \mathrm{~h}$ after the infectious stimulus. ${ }^{[5]}$

Febrile neutropenia in cancer patients on chemotherapy increases the duration of hospital stay and cost of treatment and leads to significant morbidity and mortality. Mortality from febrile neutropenia has been reported to be $5 \%$ in solid tumors and $11 \%$ in hematological malignancies. Prognosis is worst in patients with proven bacteremia with mortality rates of $18 \%$ in Gram-negative and $5 \%$ in Gram-positive bacteremia. ${ }^{[6]}$

Therefore, the present study aimed to analyze the role of IL-6 as a marker for

How to cite this article: Gupta M, Kini PG, Bhat YR,
Aroor S. Interleukin-6 versus C-reactive protein as
markers for early detection of bacteremia in febrile
neutropenia in pediatric population. Indian J Med
Paediatr Oncol 2020;41:702-6.

\section{Manasi Gupta, Pushpa G Kini, Y Ramesh Bhat, Shrikiran Aroor}

Department of Paediatrics, Kasturba Medical College and Hospital, Manipal Academy of Higher Education, Manipal, Karnataka, India

Submitted: 18 -Dec-2019 Revised: 20-Jan-2020 Accepted: 03-May-2020 Published: 29-Oct-2020

Address for correspondence: Dr. Manasi Gupta, Department of Paediatrics, Kasturba Medical College and Hospital, Manipal Academy of Higher Education, Manipal - 576 104, Karnataka, India. E-mail:manasigupta31@yahoo. in

Access this article online Website: www.ijmpo.org DOI: 10.4103/ijmpo.ijmpo_257_19 Quick Response Code:

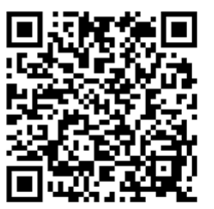


bacteremia in pediatric patients with febrile neutropenia. The other objectives of the study were to compare the levels of IL-6 versus CRP in microbiologically documented infections (MDIs), clinically documented infections (CDIs), and fever of unknown origin (FUO); and to study the prognosis and outcome of the three groups in febrile neutropenia.

\section{Materials and Methods}

\section{Ethics}

The study was approved by the Institutional Ethics Committee (ECR/146/Inst/KA/2013). An informed consent was taken from the parents of all study participants after explaining the purpose and relevance of the study to them.

\section{Study design}

A prospective observational study was conducted over a period of 18 months from January 2018 to June 2019 in the Paediatrics Department of a Tertiary Care Center in South India.

\section{Study participants}

All children aged from 1 month to 18 years having a diagnosis of hematological or other malignancies who developed febrile neutropenia during any phase of chemotherapy were included in the study. Multiple episodes of febrile neutropenia in the same child were analyzed as separate episodes. The study participants who were not willing to participate in the study and those who were discharged against medical advice were excluded from the study.

Definitions used:

- Fever: Fever is defined as a single temperature measurement of $>38.3^{\circ} \mathrm{C}\left(101^{\circ} \mathrm{F}\right)$ or a temperature of $>38.0^{\circ} \mathrm{C}\left(100.4^{\circ} \mathrm{F}\right)$ sustained over a $1 \mathrm{~h}$ period ${ }^{[7]}$

- Absolute neutrophil count (ANC): white blood cell $\times(\%$ neutrophils $+\%$ bands + other precursor cells $)$

- Neutropenia: neutropenia is defined as an ANC of $<500$ cells $/ \mathrm{mm}^{3}$ or an ANC that is expected to decrease to $<500$ cells $/ \mathrm{mm}^{3}$ during the next $48 \mathrm{~h}^{[7]}$

- Profound neutropenia: ANC is $<100$ cells $/ \mathrm{mm}^{3[7]}$

- Prolonged neutropenia: Neutropenia lasting for more than 7 days

- FUO: New onset of fever without clear clinical or microbiological evidence; fever $>38.3^{\circ} \mathrm{C}$ or $>38.0^{\circ} \mathrm{C}$ over at least $1 \mathrm{~h}$ or twice within $12 \mathrm{~h}$ without evident cause $^{[8]}$

- CDI: Fever in connection with unambiguous diagnostic signs of localized infection, for example, pneumonia, acute gastroenteritis, urinary tract infection, skin/ soft-tissue inflammation without microbiological proof or if not accessible for examination ${ }^{[8]}$

- MDI: fever with plausible pathogenic evidence (in the microbiological/time context) in addition to identified localized infection, or pathogenic agents can be found in blood culture without localized infection. ${ }^{[8]}$

\section{Data collection procedure}

A detailed history was obtained including demographic data, primary diagnosis, details of chemotherapy regime, and any prior antibiotic prophylaxis. Blood samples were collected at the onset of fever in inpatients or within $6 \mathrm{~h}$ of presentation to the hospital and sent for complete blood counts, erythrocyte sedimentation rate, CRP, IL-6, renal and liver function tests, blood culture, and sensitivity. Additional tests and investigative procedures such as urine routine, chest X-ray, and lumbar puncture were done if indicated. Antibiotics received were documented, prognosis and outcome were analyzed.

\section{Sample size}

Anticipating sensitivity of $70 \%$ for IL-6 as a marker of bacteremia with a $4 \%$ precision and $20 \%$ prevalence of MDI, minimum of 57 cases of febrile neutropenia were to be enrolled in the study.

\section{Statistical methods}

Data were analyzed using the IBM SPSS Statistics 20. Descriptive data were expressed as percentage, median, and interquartile range (IQR) or as mean and standard deviation. Statistical significance was calculated using Student's $t$-test for parametric data and Kruskal-Wallis test for nonparametric data. The association between categorical variables was assessed using Chi-square test or Fisher's exact test.

\section{Results}

A total of 32 episodes of febrile neutropenia in 25 children were analyzed.

The baseline characteristics of the study participants were as mentioned in Table 1. The majority of the study participants were <6-year-old males. The median age for the study group was 7 years (IQR: 4,12). Nutritional status was normal in 21 out of 25 children in the study group. The predominant malignancy in the study group was acute lymphoblastic leukemia (ALL) (84\%). Among children diagnosed to have ALL (21), most of them had CALLA positive B-cell ALL $(15,71.4 \%)$. There was one case of Hodgkin's lymphoma (mixed cellularity Stage 2), one case of non-Hodgkin's lymphoma and one case of extra-adrenal metastatic neuroblastoma (Stage 4).

The characteristics of the febrile neutropenia episodes are mentioned in Table 2. Febrile neutropenic episodes were seen more in the induction stage of chemotherapy. Organisms isolated in the seven cases of MDI were Klebsiella pneumoniae (in three cases), Pseudomonas aeruginosa (in two cases), coagulase-negative Staphylococcus and Staphylococcus haemolyticus in one case each. One case of $K$. pneumoniae sepsis also had 
Aspergillosis. There was a central line in situ in this case. Two children had Varicella zoster infection and one had herpes labialis. The most common focus of infection was lower respiratory tract infection confirmed by radiological evidence (14 cases). The second-most common source of infection was acute gastroenteritis (nine cases). Three cases with acute gastroenteritis also had mucositis. Multisystem involvement was seen in six cases and two out of these had hypotension and shock at presentation.

Twenty-four out of 32 cases had hemoglobin of $<11 \mathrm{~g} / \mathrm{dl}$. Eleven cases required packed red blood cell transfusion. Thrombocytopenia (platelet count $<150,000 / \mathrm{mm}^{3}$ ) was seen in 21 cases. Platelet transfusion was given in ten cases which had severe thrombocytopenia with bleeding manifestations. Profound neutropenia was seen in 18 cases.

Table 1: Baseline characteristics of the study group $(n=25)$

\begin{tabular}{lc}
\hline Characteristic & $\boldsymbol{n}(\mathbf{\%})$ \\
\hline Gender & $18(72)$ \\
Male & $7(28)$ \\
Female & \\
Age group & $12(48)$ \\
1 month-6 years & $8(32)$ \\
7-12 years & $5(20)$ \\
13-18 years & \\
Weight & $21(84)$ \\
Normal & $4(16)$ \\
Underweight (weight $<3^{\text {rd }}$ centile) & \\
Primary diagnosis & $21(84)$ \\
ALL & $1(4)$ \\
AML & $2(8)$ \\
Lymphoma & $1(4)$ \\
Solid tumor &
\end{tabular}

$\overline{\mathrm{ALL}}=$ Acute lymphoblastic leukemia, $\mathrm{AML}=$ Acute myeloid leukemia

Table 2: Characteristics of the febrile neutropenia episode $(n=32)$

\begin{tabular}{lc}
\hline Characteristic & $\boldsymbol{n ( \% )}$ \\
\hline Stage of chemotherapy & $14(43.8)$ \\
Induction & $12(37.5)$ \\
Consolidation & $6(18.7)$ \\
Maintenance & \\
Type of infection & $7(21.9)$ \\
MDI & $19(59.4)$ \\
CDI & $6(18.7)$ \\
FUO & \\
Relapse of malignancy & $3(9.4)$ \\
Yes & $29(90.6)$ \\
No & \\
Steroids in last 2 weeks & $28(87.5)$ \\
Yes & $4(12.5)$ \\
No & \\
MDI=Microbiologically documented infection, CDI=Clinically \\
documented infection, FUO=Fever of unknown origin
\end{tabular}

Granulocyte-colony stimulating factor was given in seven cases. Two cases had deranged baseline renal function test (elevated creatinine value more than the age-related upper normal limit) and four cases had deranged liver function test (elevated transaminases more than 1.5 times the age-related upper normal limit) out of which two were drug-induced hepatitis.

The median values of IL-6 and CRP in the febrile neutropenia episodes are mentioned in Table 3. It was noted that IL-6 was high in all the 32 episodes of febrile neutropenia. IL-6 values ranged from 8 to $5000 \mathrm{pg} / \mathrm{ml}$. In 14 episodes, IL-6 value was more than $100 \mathrm{pg} / \mathrm{ml}$. Gram-negative sepsis had a much higher median IL-6 value than Gram-positive sepsis and sterile blood cultures $(P=0.017)$. Similar observation was not seen with CRP values $(P=0.796$, statistical tool used: KruskalWallis test). CRP was high in 26 out of 32 episodes of febrile neutropenia. All the six episodes which had normal CRP values had sterile blood culture and CDI. CRP values ranged from 0.66 to $288 \mathrm{mg} / \mathrm{L}$. The median value of both IL-6 and CRP was highest in MDI.

Table 4 shows the correlation between type of infection and ANC. All the seven cases of MDI were associated with $\mathrm{ANC}<100 / \mu \mathrm{L}$.

The median duration of fever in the febrile neutropenia episodes was 4 days (IQR: 2,7). Fever beyond 1 week

\begin{tabular}{|c|c|c|}
\hline & $\begin{array}{l}\text { IL-6 (pg/ml) } \\
(\leq 7 \mathrm{pg} / \mathrm{ml})\end{array}$ & $\begin{array}{l}\mathrm{CRP}(\mathrm{mg} / \mathrm{L}) \\
(\leq 10 \mathrm{mg} / \mathrm{L})\end{array}$ \\
\hline $\begin{array}{l}\text { All febrile neutropenic } \\
\text { episodes: }(n=32)\end{array}$ & $73.9(25.2-151.5)$ & $52.6(18-122.2)$ \\
\hline \multicolumn{3}{|l|}{ Type of infection } \\
\hline MDI $(n=7)$ & $129(27-200.1)$ & $68(33.9-103)$ \\
\hline CDI $(n=19)$ & $48(25-128)$ & $44.2(3.9-125.7)$ \\
\hline FUO $(n=6)$ & $85(12.7-120.7)$ & $55.5(28.4-196.8)$ \\
\hline \multicolumn{3}{|l|}{ Blood culture } \\
\hline Gram-negative $(n=5)$ & $169(124-2600)$ & $60.7(25.8-188.6)$ \\
\hline Gram-positive $(n=2)$ & 17.5 & 85.5 \\
\hline Sterile $(n=25)$ & $52(21-120)$ & $44.2(8.6-127.5)$ \\
\hline
\end{tabular}

Table 4: Correlation between absolute neutrophil count and type of infection $(n=32)$

\begin{tabular}{lccc}
\hline Type of infection & \multicolumn{3}{c}{ ANC, $\boldsymbol{n}(\%)$} \\
\cline { 2 - 4 } & $\leq \mathbf{1 0 0}$ & $\mathbf{1 0 1 - 5 0 0}$ & $>\mathbf{5 0 0}$ \\
\hline MDI $(n=7)$ & $7(100)$ & 0 & 0 \\
CDI $(n=19)$ & $7(18.2)$ & $10(63.6)$ & $2(18.2)$ \\
FUO $(n=6)$ & $4(66.6)$ & $2(33.4)$ & 0 \\
\hline ANC
\end{tabular}

$\mathrm{ANC}=$ Absolute, $\mathrm{MDI}=$ Microbiologically documented infection, $\mathrm{CDI}=$ Clinically documented infection, $\mathrm{FUO}=$ Fever of unknown origin 
duration was seen in eight out of 32 episodes $(25 \%)$. Prolonged neutropenia was seen in 22 cases. Four cases of febrile neutropenia succumbed due to septic shock in the present study. All the four cases had an IL-6 value of $>100 \mathrm{pg} / \mathrm{ml}$.

The correlation between the outcome of febrile neutropenic episodes and type of infection is shown in Table 5. MDI were associated with the worst prognosis as three cases succumbed in this group, $42.9 \%$ of the cases had fever beyond 1 week and prolonged neutropenia was seen in $85.8 \%$ of the cases.

\section{Discussion}

Most of the childhood cancers have a male preponderance with a male to female ratio of 1.2:1. ${ }^{[9,10]}$ However, in the present study, a male to female ratio of 2.5:1 was seen. The most commonly seen childhood cancer in India is leukemia which accounts for $25 \%-40 \%$ of all the cancers. ${ }^{[11]}$ In the present study, $84 \%$ of the children had ALL.

The incidence of bacteremia in febrile neutropenic children depends on extent and duration of neutropenia, antibiotics prophylaxis and use of central venous catheters. The incidence rate of bacteremia ranges from $5 \%$ to $35 \%$ in febrile neutropenic children who are not receiving antibiotic prophylaxis. ${ }^{[8,12]}$ In the present study, all the children were receiving antibiotic prophylaxis and the incidence of bacteremia was $21.9 \%$. A change in the trend of bacterial agents causing bloodstream infections in febrile neutropenic patients has been seen due to the routine use of antimicrobial prophylaxis. In the 1960s-1970s, a predominance of Gram-negative bacteria was seen but over the last few decades, Gram-positive bacteria are

\begin{tabular}{|c|c|c|c|}
\hline \multicolumn{4}{|c|}{$\begin{array}{l}\text { Table 5: Correlation between the outcome of the febrile } \\
\text { neutropenic episode and type of infection }(n=32)\end{array}$} \\
\hline \multirow{2}{*}{ Outcome } & \multicolumn{3}{|c|}{ Type of infection, $n(\%)$} \\
\hline & $\operatorname{MDI}(n=7)$ & CDI $(n=19)$ & FUO $(n=6)$ \\
\hline \multicolumn{4}{|c|}{ Primary outcome } \\
\hline Survived & $4(57.1)$ & $18(94.7)$ & $6(100)$ \\
\hline Succumbed & $3(42.9)$ & $1(5.3)$ & 0 \\
\hline \multicolumn{4}{|c|}{$\begin{array}{l}\text { Duration of fever } \\
\text { (days) }\end{array}$} \\
\hline$\leq 7$ & $4(57.1)$ & $15(78.9)$ & $5(83.3)$ \\
\hline$>7$ & $3(42.9)$ & $4(21.1)$ & $1(16.7)$ \\
\hline \multicolumn{4}{|c|}{$\begin{array}{l}\text { Duration of } \\
\text { neutropenia (days) }\end{array}$} \\
\hline$\leq 7$ & $1(14.2)$ & $7(36.8)$ & $2(33.3)$ \\
\hline$>7$ & $6(85.8)$ & $12(63.2)$ & $4(66.7)$ \\
\hline \multicolumn{4}{|c|}{$\begin{array}{l}\text { Duration of break } \\
\text { in chemotherapy } \\
\text { (days) }\end{array}$} \\
\hline$\leq 7$ & $1(14.2)$ & $6(31.6)$ & $2(33.3)$ \\
\hline$>7$ & $6(85.8)$ & $13(68.4)$ & $4(66.7)$ \\
\hline
\end{tabular}

MDI=Microbiologically documented infection, $\mathrm{CDI}=\mathrm{Clinically}$ documented infection, $\mathrm{FUO}=$ Fever of unknown origin isolated more often. ${ }^{[13]}$ However, Gram-negative organisms are still associated with significant mortality and in some of the recent studies, Gram-negative bacteremia has been seen more commonly than Gram-positive bacteremia. ${ }^{[13,14]}$ In the present study also, in 5 out of 7 cases of MDI, Gram-negative bacteremia was seen and 3 cases of Gram-negative bacteremia succumbed. All the cases of MDI had profound neutropenia and majority had prolonged neutropenia. Therefore, febrile profound neutropenic patients need to be started on appropriate antibiotic therapy at the onset of symptom of fever.

Febrile neutropenic patients need to be started on antibiotics as early as possible to reduce the associated morbidity and mortality. Therefore, markers predicting the risk and type of bacteremia can help in better treatment and prognostication of the febrile neutropenic episode. IL-6 has been reported as a more sensitive marker of Gram-negative sepsis. ${ }^{[1,4]}$ In the present study, the median value of Il-6 was 3-10-fold higher in Gram-negative sepsis as compared to Gram-positive sepsis and sterile blood cultures. Similar trend was not observed with CRP. A larger randomized study taking into account other contributing factors such as levels of CRP and IL-6 in viral and fungal infections; risk of mortality and cost-effectiveness can provide more concrete evidence toward this observation. However, CRP remains a cheaper and useful marker of sepsis as the median values of both IL-6 and CRP was highest in MDI.

Higher IL-6 levels have also been associated with an increased risk of mortality and an association between mean concentration of plasma IL-6 over time and the mortality rate has been studied. ${ }^{[15,16]}$ However, due to financial constraints, serial IL-6 values could not be obtained.

\section{Conclusion}

IL-6 is a better predictor of Gram-negative bacteremia than CRP in febrile neutropenic children while on chemotherapy. However, the statistical significance of this association could not be ascertained due to the small sample size

CRP estimation is cheaper and is still a valuable test in sepsis where IL-6 test is not feasible.

\section{Financial support and sponsorship}

Nil.

\section{Conflicts of interest}

There are no conflicts of interest.

\section{References}

1. von Lilienfeld-Toal $\mathrm{M}$, Dietrich MP, Glasmacher A, Lehmann L, Breig P, Hahn C, et al. Markers of bacteremia in febrile neutropenic patients with hematological malignancies: Procalcitonin and IL-6 are more reliable than C-reactive protein. Eur J Clin Microbiol Infect Dis 2004;23:539-44.

2. Holub M, Lawrence DA, Andersen N, Davidová A, Beran O, Marešová $\mathrm{V}$, et al. Cytokines and chemokines as biomarkers 
of community-acquired bacterial infection. Mediators Inflamm 2013;2013:190145.

3. Hou T, Huang D, Zeng R, Ye Z, Zhang Y. Accuracy of serum interleukin (IL)-6 in sepsis diagnosis: A systematic review and meta-analysis. Int J Clin Exp Med 2015;8:15238-45.

4. Engel A, Mack E, Kern P, Kern WV. An analysis of interleukin-8, interleukin-6 and C-reactive protein serum concentrations to predict fever, Gram-negative bacteremia and complicated infection in neutropenic cancer patients. Infection 1998;26:213-21.

5. Oda S, Hirasawa $H$, Shiga $H$, Nakanishi $K$, Matsuda $K$, Nakamua M. Sequential measurement of IL-6 blood levels in patients with systemic inflammatory response syndrome (SIRS)/ sepsis. Cytokine 2005;29:169-75.

6. de Naurois J, Novitzky-Basso I, Gill MJ, Marti FM, Cullen MH, Roila F, et al. Management of febrile neutropenia: ESMO Clinical Practice Guidelines. Ann Oncol 2010;21 Suppl 5:v252-6.

7. Freifeld AG, Bow EJ, Sepkowitz KA, Boeckh MJ, Ito JI, Mullen CA, et al. Clinical practice guideline for the use of antimicrobial agents in neutropenic patients with cancer: 2010 update by the infectious diseases Society of America. Clin Infect Dis 2011;52:56-93.

8. Buchheidt D, Böhme A, Cornely OA, Fätkenheuer G, Fuhr HG, Heussel $\mathrm{G}$, et al. Infectious diseases working party (AGIHO) of the German Society of Hematology and Oncology (DGHO). Diagnosis and treatment of documented infections in neutropenic patients - Recommendations of the infectious diseases working party (AGIHO) of the German Society of Hematology and
Oncology (DGHO). Ann Hematol 2003;82 Suppl 2:S127-32.

9. Stiller C, editor. Childhood Cancer in Britain: Incidence Survival, Mortality. Oxford: Oxford University Press; 2007.

10. Gurney JG, Bondy ML. Epidemiology of childhood cancer. In: Pizzo PA, Poplack DG, editors. Principles and Practice of Pediatric Oncology. $5^{\text {th }}$ ed. Philadelphia: Lippincott Williams and Wilkins; 2006. p. 2-14.

11. Arora RS, Eden TO, Kapoor G. Epidemiology of childhood cancer in India. Indian J Cancer 2009;46:264-73.

12. Escande MC, Herbrecht R. Prospective study of bacteraemia in cancer patients. Results of a French multicentre study. Support Care Cancer 1998;6:273-80.

13. Mandal PK, Maji SK, Dolai TK, De R, Dutta S, Saha S, et al. Micro-organisms Associated with febrile neutropenia in patients with Haematological Malignancies in a Tertiary Care Hospital in Eastern India. Indian J Hematol Blood Transfus 2015;31:46-50.

14. Taj M, Farzana T, Shah T, Maqsood S, Ahmed SS, Shamsi TS. Clinical and microbiological profile of pathogens in febrile neutropenia in hematological malignancies: A single center prospective analysis. J Oncol 2015;2015:596504.

15. Patel RT, Deen KI, Youngs D, Warwick J, Keighley MR. Interleukin 6 is a prognostic indicator of outcome in severe intra-abdominal sepsis. Br J Surg 1994;81:1306-8.

16. Pinsky MR, Vincent JL, Deviere J, Alegre M, Kahn RJ, Dupont E. Serum cytokine levels in human septic shock. Relation to multiple-system organ failure and mortality. Chest 1993;103:565-75. 